DELLA VECCHIA, P.T.; KOCH, P.S.; KIKUCHI, M. Vera: Nova cultivar de alface crespa resistente ao florescimento prematuro. Horticultura Brasileira, Brasília, v. 17, n.2, p. 171, julho 1999.

\title{
VERA: Nova cultivar de alface crespa resistente ao florescimento pre- maturo.
}

\author{
Paulo T. Della Vecchia; Paulo S. Koch; Masami Kikuchi \\ Agroflora S.A., C. Postal 427, 12.900-000 Bragança Paulista - SP.
}

\section{RESUMO}

Vera é uma nova cultivar de alface crespa resistente ao florescimento prematuro selecionada através do método genealógico a partir do cruzamento entre as cultivares Verônica e Slow Bolting. 'Vera' corresponde à multiplicação, em escala comercial, da linhagem $\mathrm{F}_{10}$ AF 470. Em ensaios conduzidos no período de verão nas principais regiões produtoras do estado de São Paulo (Mogi das Cruzes, Campinas, Ibiúna, etc) o início da emissão da haste floral em Vera foi retardado em quinze a vinte dias quando comparado ao da cultivar Grand Rapid e em cinco a sete dias quando comparado ao da cultivar Verônica.

Palavras-chave: Lactuca sativa L., florescimento prematuro, resistência.

\begin{abstract}
VERA: new cultivar of crisp loose leaf type lettuce resistant to bolting.

Vera is a new cultivar of crisp loose leaf type lettuce resistant to bolting. It was obtained through pedigree selection from the cross between cultivars Verônica and Slow Bolting. Vera corresponds to the commercial increase of the $F_{10}$ breeding line AF 470. Based on summer trials carried out in the main production areas of São Paulo state (Mogi das Cruzes, Campinas, Ibiuna, etc) bolting in Vera was delayed by fifteen to twenty days when compared to the cultivar Grand Rapid and by five to seven days when compared to cultivar Verônica.
\end{abstract}

Keywords: Lactuca sativa L., bolting, resistance.

\section{(Aceito para publicação em 08 de março de 1999)}

$\mathrm{V}$ era é uma nova cultivar de alface crespa, resistente ao florescimento prematuro induzido por altas temperaturas. Em ensaios conduzidos nas principais regiões produtoras de alface do estado de São Paulo (Mogi das Cruzes, Campinas, Ibiúna, etc), durante os meses de verão de 1995/96 e de 1996/97, 'Vera' teve performance consistentemente superior à das cultivares tradicionalmente cultivadas na região, Grand Rapid e Verônica.

\section{ORIGEM}

'Vera' foi selecionadas através do método genealógico, a partir do cruzamento entre as cultivares Verônica e Slow Bolting. Os trabalhos de avaliação e seleção das melhores linhagens e, de plantas dentro das linhagens, foram conduzidos nas Estações Experimentais de Bragança Paulista-SP e de Petrolina-PE, durante o período de 1989 a 1996. 'Vera' corresponde à multiplicação, em escala comercial, da linhagem $\mathrm{F}_{10}$ AF 470.

\section{DESCRIÇÃO}

'Vera' apresenta plantas vigorosas com folhas crespas, bem mais acentuadas do que as da cultivar Verônica, eretas e de coloração verde-clara brilhante, semelhantes às da cultivar Grand Rapid. Suas folhas basais são, em média, 2 a 3 $\mathrm{cm}$ mais curtas e 2 a $4 \mathrm{~cm}$ mais largas do que as da cv.Verônica. 'Vera' apresenta, em média, menor número de folhas $(2 \mathrm{a}$ 3 folhas) do que a cultivar Verônica. Seu ciclo, da semeadura ao ponto ideal de colheita para o mercado, varia de 50 a 70 dias conforme a região e época de cultivo. 'Vera' apresenta excelente resistência ao florescimento prematuro em cultivos de verão. Nas principais regiões produtoras do estado de São Paulo (Mogi das Cruzes, Campinas, Ibiúna, etc) o início da emissão da haste floral, nestas condições de cultivo, é retardado em quinze a vinte dias quando comparado ao da cultivar Grand Rapid e em cinco a sete dias quando comparado ao da cultivar Verônica. Entretanto, 'Vera' é ligeiramente mais sensível à queima de bordas das folhas, no cultivo de verão, quando comparada à cultivar Verônica. 'Vera' apresenta também excelente performance em cultivo de inverno a campo aberto e em cultivo hidropônico durante o ano todo. Vera produz sementes de coloração marron-escura.

\section{DISPONIBILIDADE DE SEMENTES}

Sementes da nova cultivar estão sendo comercializadas pela Agroflora S.A., desde Janeiro de 1998, através de lojas especializadas de sementes. 